\title{
PREPARAÇÃO E CARACTERIZAÇÃO DE HIDROGÉIS DE POLI(ÁLCOOL VINÍLICO) CARREGADOS COM NANOCRISTAIS DE CELULOSE.
}

\section{Guilherme F. Alves*, Ivanei F. Pinheiro, Lucia H. Innocentini Mei}

\section{Resumo}

Este trabalho têm como principal objetivo avaliar as propriedades mecânicas de hidrogéis de Poli(Álcool Vinílico) carregados com nanocristais de celulose. Os nanocristais de celulose foram preparados a partir de uma reação de hidrólise ácida com solução de ácido súlfurico a 55\%v/v, sendo caracterizados por Espectroscopia no Infravermelho(FTIR), Ângulo de Contato e Microscópio Eletrônico de Transmissão (MET). Os hidrogéis seriam produzidos através de uma reação de reticulação por policondensação utilizando glutaraldeído como agente reticulante e caracterizados através de grau de intumescimento, análise termogravimétrica (TGA), Calorimetria Exploratória Diferencial (DSC) e Microscópio Eletrônico de Transmissão (MET), entretanto o cancelamento do projeto devido ao início de um estágio obrigatório impossibilitou a conclusão do projeto.

Palavras-chave:

Biomateriais, Hidrogel, Nanocristais de celulose.

\section{Introdução}

Biomateriais são materiais de origem natural ou sintética, e normalmente feito de vários componentes que interagem com sistemas biológicos. Os hidrogéis são, basicamente, redes de polímeros hidrofílicos reticulados, com capacidade de reter grandes quantidades de água em sua estrutura, sem a perda de sua forma tridimensional. É comum a utilização de hidrogéis nas áreas de biotecnologia, farmacologia e medicina, principalmente como suporte para liberação de medicamentos de forma progressiva, além do tratamento de feridas. Muitos materiais, tanto naturais como sintéticos, se encaixam na definição de hidrogéis; entretanto, os sintéticos apresentam maior interesse no mercado devido as suas melhores propriedades, como longa vida útil, alta capacidade de absorção e retenção de água, e melhor resistência a variações de temperatura. A celulose é um recurso renovável e de grande abundância, que pode ser usada para confecção de novos materiais altamente hidrofílicos, biocompatíveis e ecologicamente corretos apropriados para diferentes aplicações. Devido ao grande número de grupos hidroxila, a produção de hidrogéis a base de celulose tornou-se viável. Desta forma este trabalho, visa estudar a preparação e caracterização de hidrogéis carregados com nanocristais de celulose, para também melhorar a resistência da rede tridimensional.

\section{Resultados e Discussão}

Os Nanocristais foram preparados pelo método Hassan et al. (2012) e Pinheiro (2016) a partir da celulose microcristalina (MC 500).

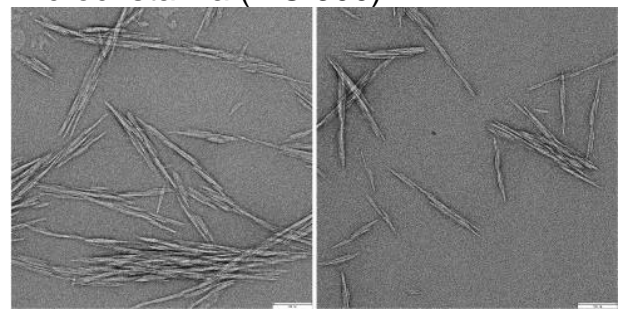

Figura 1. Imagem obtida por Microscópio Eletrônico de Transmissão (MET) dos nanocristais de celulose sintetizados (CNC)

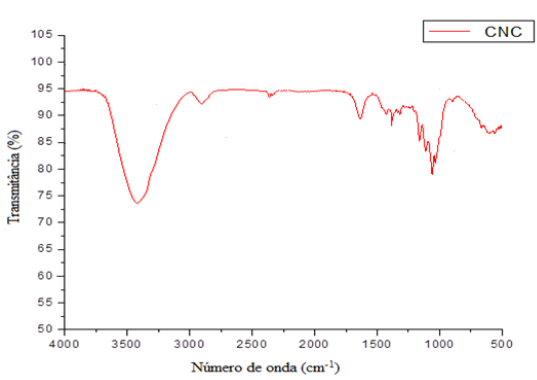

Figura 2. Espectro no infravermelho dos nanocristais de celulose

$\mathrm{Na}$ figura 1 são exibidos os espectros FTIR de nanocristais de celulose. As bandas próximas a 1100 $\mathrm{cm}^{-1}$ são características de vibrações de ligação $\mathrm{C}-\mathrm{O}$ de alcoóis secundários; entre 2850 e $2960 \mathrm{~cm}^{-1}$ aparecem bandas dos grupamentos alquila $\left(-\mathrm{CH}_{3}\right.$ e $\left.-\mathrm{CH}_{2}-\right)$ e as bandas próximas de $3500 \mathrm{~cm}^{-1}$ representam 0 grupamento $-\mathrm{OH}$ da celulose.

A análise via Ângulo de contato demonstrou a característica hidrofílica da nanocelulose, devido a total absorção de água em um curto período de tempo.

\section{Conclusões}

A preparação e caracterização dos nanocristais de celulose foi realizada com sucesso e no período programado (julho-dez/2017). Obteve-se partículas na ordem nanométricas com propriedades típicas da celulose, as quais poderiam ser utilizadas como reforço polimérico. O início de um estágio obrigatório fez com o que o aluno cancelasse a bolsa em dez-2017, impossibilitando a confecção dos hidrogéis, aos quais seriam produzidos nos próximos 6 meses. $O$ excesso de atividades atreladas a graduação e ao estágio interferiu para a continuação do projeto de forma voluntária.

\section{Agradecimentos}

A Pra Dr. Lucia Mei pela oportunidade e a PIBIC pela bolsa concedida ao aluno.

HASSAN et al. Polycaprolactone/Modified Bagasse Whisker Nanocomposites with Improved Moisture-Barrier and Biodegradability Properties. Journal of Applied Polymer Science, v. 125, p. 10-19, 2012.

PINHEIRO, Ivanei Ferreira et al. Preparação e caracterização de biocompósitos híbridos baseados em nanocristais de celulose de fibras de munguba. 2016. 